\title{
CURRENT SOURCE BASED ON H-BRIDGE INVERTER WITH OUTPUT LCL FILTER
}

\author{
Vojtech Blahnik $^{* * *}$ _ Jakub Talla ${ }^{*}$ Z Zdenek Peroutka ${ }^{*}, * *$
}

\begin{abstract}
The paper deals with a control of current source with an LCL output filter. The controlled current source is realized as a single-phase inverter and output LCL filter provides low ripple of output current. However, systems incorporating LCL filters require more complex control strategies and there are several interesting approaches to the control of this type of converter. This paper presents the inverter control algorithm, which combines model based control with a direct current control based on resonant controllers and single-phase vector control. The primary goal is to reduce the current ripple and distortion under required limits and provides fast and precise control of output current. The proposed control technique is verified by measurements on the laboratory model.
\end{abstract}

K e y w ord s: LCL output filter

\section{INTRODUCTION}

Many grid connected power electronic systems, such as Statcoms [1], UPFCs [2], and distributed generation system converters (eg renewable energy sources [3]), use a voltage source inverter connected to the supply network through a filter. This filter, typically a series inductance, reduces the switching harmonics entering to the distribution network. An alternative filter is a LCL, which can achieve reduced levels of harmonic distortion at lower switching frequencies and with less inductance value. This approach was massively deployed for three-phase power converter (for example [4]). However, single-phase power converter uses LCL filters rarely, because it requires more complex control strategies. Until now, several methods have been proposed in literature for the control of singlephase inverters. Hysteresis control and delta modulation controls are robust and simple, but its variable switching frequency expects special adaptation likes [5]. Widely used control technique is vector control based on simple PI controllers [6] and [7], but these methods show a very slow dynamic behaviour for single-phase system. Very promising control techniques are based on predictive controllers [8] and [9], this kind of controllers is high sensitive to the system model accuracy. Simple and very effective control method is direct current control based on PR controller [10]. They are capable to track sinusoidal references of arbitrary frequencies of both, positive and negative sequences, with zero steady state error.

The objective of this research was design of perspective control for single-phase controlled current source with output LCL filter for current ripple reducing. Designed control must precisely control generated current with arbitrary power factor in full power range. Furthermore it is necessary to eliminate the current distortions caused by dead-times and other power converters non-linearity, see $e g$ [11]. This paper describes in detail the enhanced control strategy and presents the experiments made on developed small-scale converter prototype with maximal output power $2 \mathrm{kVA}$. Tests are performed for the most problematic power converter conditions, such as are requirements for generating capacitive and inductive reactive current. The laboratory small-scale prototype consist of single-phase ac source $\left(v_{a c}=230 \mathrm{~V}_{\mathrm{RMS}}\right)$, symmetrical LCL filter $\left(L_{1}=L_{2}=800 \mu \mathrm{H}, R_{L 1}=R_{L 2}=100 \mathrm{~m} \Omega\right.$, $C=60 \mu \mathrm{F})$, single-phase converter based on IGBT tech$\operatorname{nology}\left(f_{\text {switch }}=10 \mathrm{kHz}, t_{\text {deadtimes }}=3.3 \mu \mathrm{s}\right)$ and dc source $\left(V_{d c}=420 \mathrm{~V}\right)$. The current source power circuit is shown in Fig. 1.

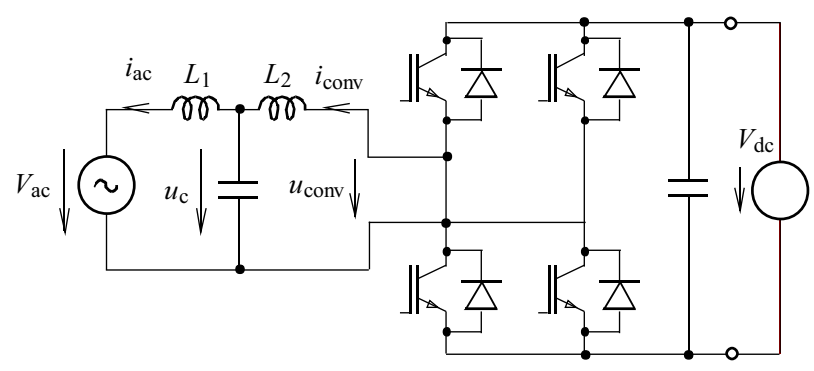

Fig. 1. Power circuit of controlled current source with LCL filter

\section{CONVERTER CONTROL STRATEGY}

The proposed control of current source must provide fast and well control of output current $\left(i_{a c}\right)$ with a precisely defined phase shift against ac source $\left(v_{a c}\right)$. That is the reason for using an accurate voltage synchronization method intended to single-phase systems. In this case,

\footnotetext{
${ }^{*}$ Regional Innovation Centre for Electrical Engineering (RICE), Faculty of Electrical Engineering, ${ }^{* *}$ Department of Electromechanical Engineering and Power Electronics, Faculty of Electrical Engineering, University of West Bohemia, Univerzitní 26, 30614 Plzeň, Czech Republic lucke@kev.zcu.cz, talic@rice.zcu.cz, peroutka@ieee.org
} 


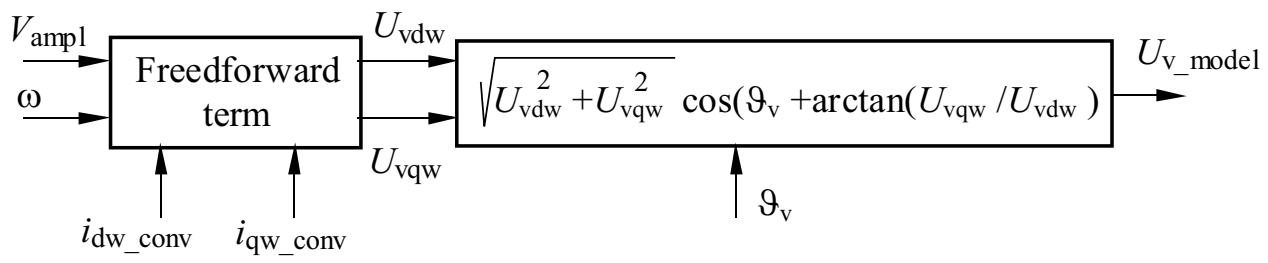

Fig. 2. Feedforward calculation — model part of the control structure



Fig. 3. Direct current control based on PR controller — feedback part of the control structure

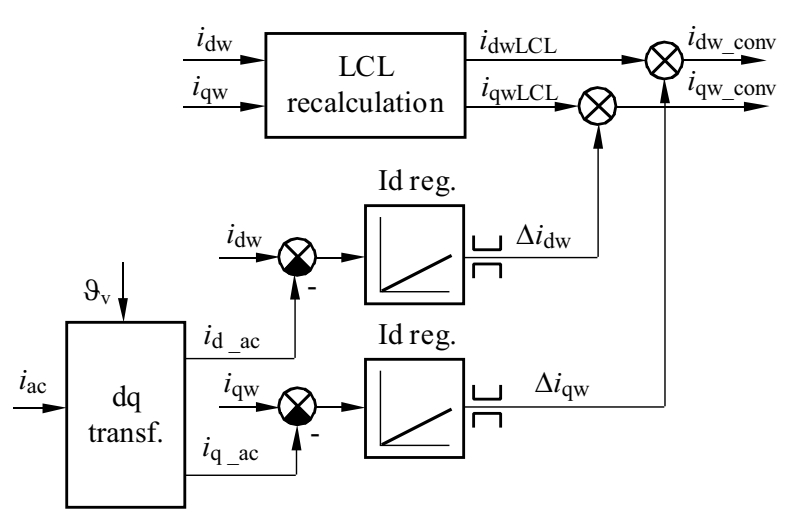

Fig. 4. Converter current components recalculation - compensation of LCL filter influence

the sliding DFT (discrete Fourier transformation) synchronization has been chosen. The output signals of DFT voltage synchronization are the position of voltage vector $\left(V_{a c}\right)$ and the voltage amplitude $\left(V_{\mathrm{ampl}}\right)$. Signal $V_{\text {ampl }}$ is used to calculate mathematical model of converter and signal $\vartheta_{v}$ is used across whole control structure.

The feedforward and direct current control were chosen to achieve very fast and precise current control. The feedforward compensation uses knowledge of ac source voltage components $\left(\vartheta_{v}\right.$ and $\left.V_{\text {ampl }}\right)$, required converter current components $\left(i_{\mathrm{dw} \text { _conv }}, i_{\mathrm{qw} \_ \text {conv }}\right)$ and simplified model of LCL filter (there is only calculation with inductance part $L_{1}$ and $L_{2}$ of the filter). The output signals ( $U_{\mathrm{vdw}}$ and $U_{\mathrm{vqw}}$, are in $d, q$ virtual revolting references frame linked to space vector of ac voltage) are calculated by equations (1) and (2). The final feedforward term ( $U_{\text {v_model }}$ ) is calculated by equation (3) as a shown in Fig. 2. The direct current control is implemented by proportional resonant $(\mathrm{PR})$ controller with the pass- frequency $\omega=2 \pi 50 \mathrm{~Hz}$ (pass-frequency is equal to the frequency of ac source), this type of controller is described in [12]. The controller provides control of converter current $\left(i_{\text {conv }}\right)$ to required value $\left(i_{\mathrm{w}_{-} \text {conv }}\right)$, which is calculated from requirements for converter current com- ponents $\left(i_{\mathrm{dw} \text { _conv }}, i_{\mathrm{qw} \_ \text {conv }}\right)$. This calculation is computed by equation (4) and the full direct current control structure with $\mathrm{PR}$ controller is illustrated in Fig. 3.

$$
\begin{gathered}
U_{v d w}=-\omega\left(L_{1}+L_{2}\right) i_{q w_{\_} c o n v} \\
U_{v q w}=V_{a m p l}+\omega\left(L_{1}+L_{2}\right) i_{d w_{-} c o n v} \\
U_{v \_ \text {model }}=\sqrt{U_{v d w}^{2}+U_{v q w}^{2}} \cos \left(\vartheta_{v}+\arctan \frac{U_{v q w}}{U_{v d w}}\right) \\
i_{w_{-} \text {conv }}=\sqrt{i_{d w_{\_} c o n v}^{2}+i_{q w_{\_} c o n v}^{2}} \cos \left(\vartheta_{v}+\arctan \frac{i_{q w_{-} c o n v}}{i_{d w_{-} c o n v}}\right) .
\end{gathered}
$$

To achieve precise control of output current $\left(i_{\mathrm{ac}}\right)$ it is important to compensate the auxiliary effects of LCL filter. In this case, voltage losses and output current phase shift are compensated. The compensation of LCL filter is realized by using of forward LCL model calculation and by simplified vector control. The mathematical model inaccuracies are compensated by two integral controllers (Id reg. and Iq reg.) for active and reactive current part $\left(\Delta i_{\mathrm{dw}}\right.$ and $\left.\Delta i_{\mathrm{qw}}\right)$. The mathematical model of LCL filter is based on two basic equations (5) and (6). By subsequent modifications and transformation into $d, q$ "virtual" revolving system are obtained the final equations (7) and (8). These equations are used for the conversion of output currents requirements $\left(i_{\mathrm{dw}}, i_{\mathrm{qw}}\right)$ to feedforward currents requirements $\left(i_{\mathrm{dwLCL}}, i_{\mathrm{qwLCL}}\right)$. The final converter currents requirements are signals $i_{\mathrm{dw} \_ \text {conv }}$ and $i_{\text {qw_conv }}$. These signals are calculated by sum of feedforward currents $i_{\mathrm{dwLCL}}$ and $i_{\mathrm{qwLCL}}$ with feedback signals $\Delta i_{\mathrm{dw}}$ and $\Delta i_{\mathrm{qw}}$ from integral controllers. The resulted signals $\left(i_{\mathrm{dw} \text { _conv }}\right.$ and $\left.i_{\mathrm{qw} \_c o n v}\right)$ are requirements for converter current $i_{\text {conv }}$, as illustrated in Fig. 4 . The $d q$ transformation block uses principle for the fast decomposition (this method is not resistant against disturbances) like [8].

$$
\begin{aligned}
i_{c o n v} & =i_{a c}+C \frac{\mathrm{d} u_{c}}{\mathrm{~d} t}, \\
u_{c} & =V_{a c}+R_{1} i_{a c}+L_{1} \frac{\mathrm{d} i_{a c}}{\mathrm{~d} t},
\end{aligned}
$$




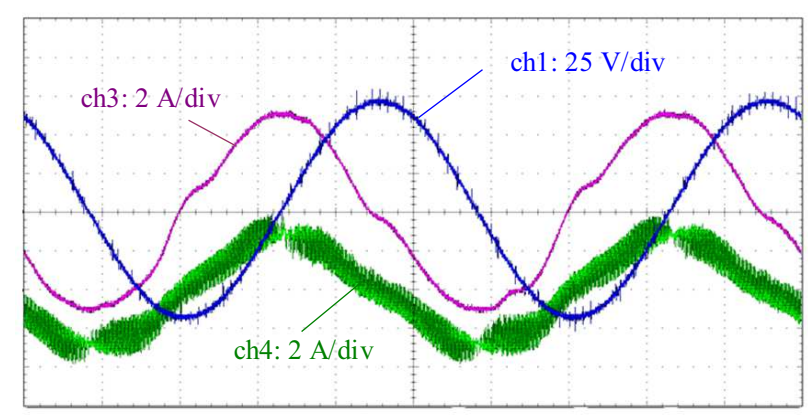

$4 \mathrm{~ms} / \mathrm{div}$

Fig. 5. Current source steady-stay — without harmonic compensatin (current components: $i_{\mathrm{dw}}=5 \mathrm{~A}, i_{\mathrm{qw}}=0 \mathrm{~A}$ ), ch1: ac source voltage $v_{\text {ac }}\left[25 \mathrm{~V} /\right.$ div], ch3: output current $i_{\text {ac }}[2 \mathrm{~A} / \operatorname{div}]$, ch4: current on converter side $i_{\text {conv }}[2 \mathrm{~A} / \operatorname{div}]$

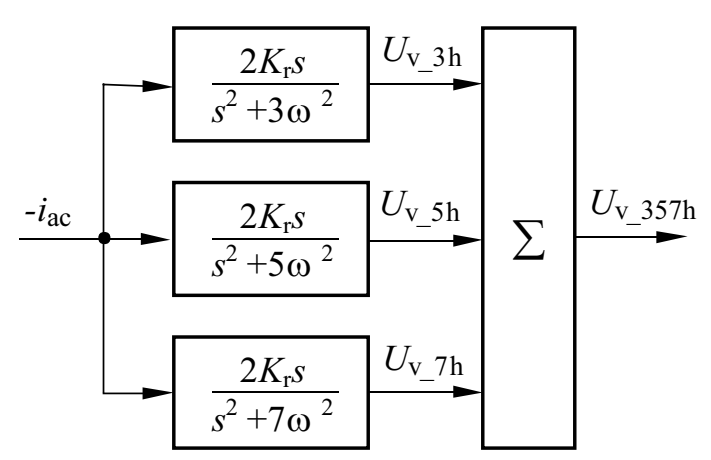

Fig. 6. Harmonic compensation - compensation by three resonant controllers $(150 \mathrm{~Hz}, 250 \mathrm{~Hz}, 350 \mathrm{~Hz})$



$$
i_{q w L C L}=\omega R_{1} C i_{d w}+\left(1-\omega^{2} L_{1} C\right) i_{q w}
$$

The behavior of classical IGBT inverter is nonlinear including dead time effects influences and current dependent nonlinear voltage drops. It leads to output currents distortion as a shown in Fig. 5. These distortions appear as a characteristics harmonics components at output current spectra. For that reason harmonics components are compensated by resonant controllers with selective pass frequency $(150 \mathrm{~Hz}, 250 \mathrm{~Hz}$ and $350 \mathrm{~Hz})$ as presented in Fig. 6. More information about low-frequency harmonic compensation by resonant controllers was published $e g$ in [13].

The final designed control algorithm is composed of these five parts: voltage synchronization, feedforward calculation, compensation of LCL filter influence, harmonic compensation and direct current control. The final modulation signal $\left(U_{\mathrm{PWM}}\right)$ is input signal for PWM. This UPWM signal is a sum of three signals $U_{\mathrm{v} \_ \text {model }}, U_{\mathrm{v}_{-} 357 \mathrm{~h}}$, $U_{\mathrm{v} \_P R}$. The complete block control diagram for controlled current source is depicted in Fig. 7. The zero vectors alternating method described in [11] for PWM modulation is used. This PWM method ensures double of current ripple frequency with the comparison to switching frequency of IGBTs.

\section{EXPERIMENTAL RESULTS}

The current source behaviour was tested on small-scale converter prototype with output power $2 \mathrm{kVA}$. The power circuit of this prototype is shown in Fig. 1. Converter is

Fig. 7. Designed control for controlled current source with output LCL filter 




$4 \mathrm{~ms} / \mathrm{div}$

Fig. 8. Current source behaviour under blocking firing signals, ch1: ac source voltage $v_{\mathrm{ac}}[100 \mathrm{~V} / \mathrm{div}]$, ch2: dc voltage $v_{\mathrm{dc}}[250 \mathrm{~V} / \mathrm{div}]$, ch3: output current $i_{\mathrm{ac}}$ [5 A/div], ch4: current on converter side $i_{\text {conv }}[5 \mathrm{~A} / \mathrm{div}]$

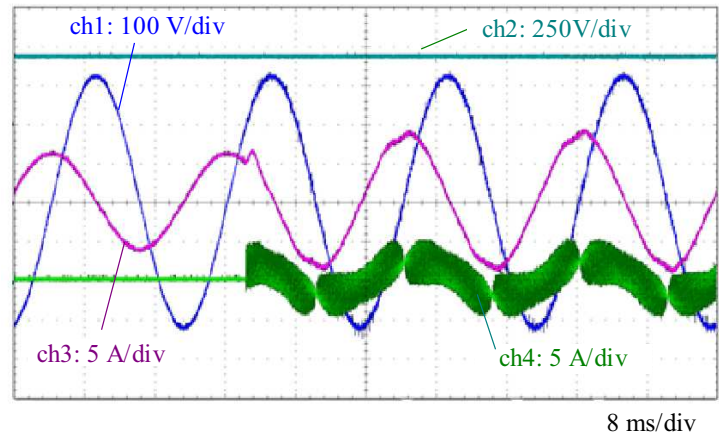

Fig. 10. Current source start-up (current components: $i_{\mathrm{dw}}=9 \mathrm{~A}$, $\left.i_{\mathrm{qw}}=0 \mathrm{~A}\right), \operatorname{ch} 1:$ ac source voltage $v_{\mathrm{ac}}[100 \mathrm{~V} / \mathrm{div}]$, ch2: dc voltage $v_{\mathrm{dc}}[250 \mathrm{~V} / \mathrm{div}]$, ch3: output current $i_{\mathrm{ac}}[5 \mathrm{~A} / \mathrm{div}]$, ch4: current on converter side $i_{\text {conv }}[5 \mathrm{~A} / \mathrm{div}]$

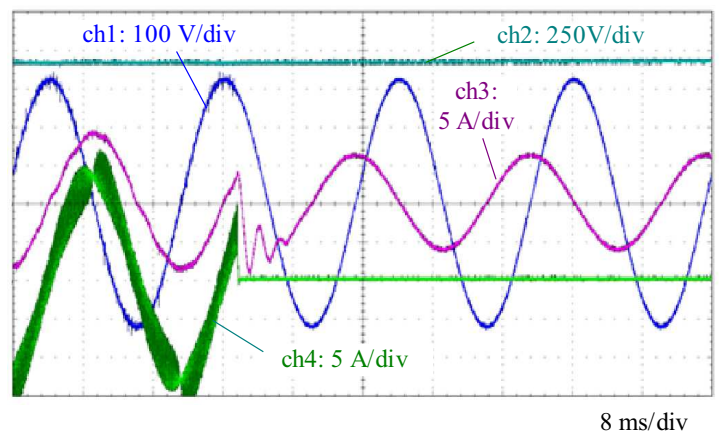

Fig. 12. Current source shutdown (current components: $i_{d w}=-9 \mathrm{~A}$, $\left.i_{q w}=0 \mathrm{~A}\right)$, ch1: ac source voltage $V_{a c}[100 \mathrm{~V} / \mathrm{div}]$, ch2: dc voltage $v_{d c}[250 \mathrm{~V} / \mathrm{div}]$, ch3: output current $i_{a c}[5 \mathrm{~A} / \mathrm{div}]$, ch4: current on converter side $i_{\text {conv }}[5 \mathrm{~A} / \mathrm{div}]$

fed by dc source $\left(V_{\mathrm{dc}}=420 \mathrm{~V}\right)$ and the output LCL filter is connected directly to terminals of ac source $\left(v_{\mathrm{ac}}=\right.$ $230 \mathrm{~V})$. The converter current is rippling with $20 \mathrm{kHz}$ for $10 \mathrm{kHz}$ switching frequency (caused by zero vector alternating modulation) and output current $\left(i_{\mathrm{ac}}\right)$ is almost without ripple (causing by correct function of LCL filter). The current source control has been implemented in the fixed-point digital signal processor Texas Instruments TMS320F 2812 with sampling frequency $50 \mu$ s (that is absolutely sufficient computing time for control algorithm implementation).

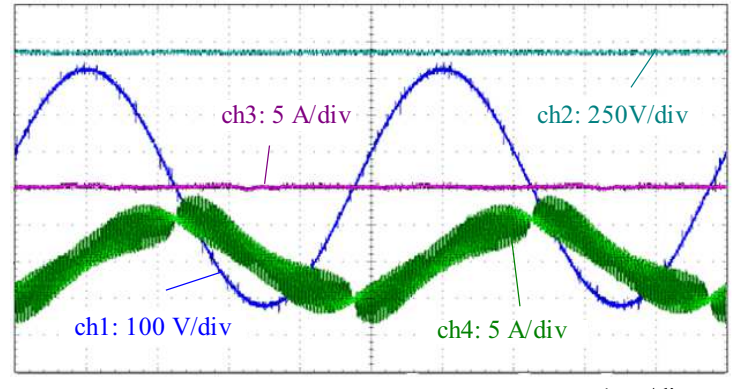

$4 \mathrm{~ms} / \mathrm{div}$

Fig. 9. Current source under steady-stay (current components: $\left.i_{\mathrm{dw}}=0 \mathrm{~A}, i_{\mathrm{qw}}=0 \mathrm{~A}\right)$, ch1: ac source voltage $v_{\mathrm{ac}}[100 \mathrm{~V} / \mathrm{div}]$, ch2: dc voltage $v_{\mathrm{dc}}[250 \mathrm{~V} / \mathrm{div}]$, ch3: output current $i_{\mathrm{ac}}[5 \mathrm{~A} / \mathrm{div}]$, ch4: current on converter side $i_{\text {conv }}[5 \mathrm{~A} / \mathrm{div}]$



Fig. 11. Current source start-up (current components: $i_{\mathrm{dw}}=$ $\left.-9 \mathrm{~A}, i_{\mathrm{qw}}=0 \mathrm{~A}\right), \operatorname{ch} 1$ : ac source voltage $v_{\mathrm{ac}}[100 \mathrm{~V} / \mathrm{div}], \operatorname{ch} 2$ : dc voltage $v_{\mathrm{dc}}[250 \mathrm{~V} / \mathrm{div}]$, ch3: output current $i_{\mathrm{ac}}[5 \mathrm{~A} / \mathrm{div}], \operatorname{ch} 4$ : current on converter side $i_{\text {conv }}[5 \mathrm{~A} /$ div $]$

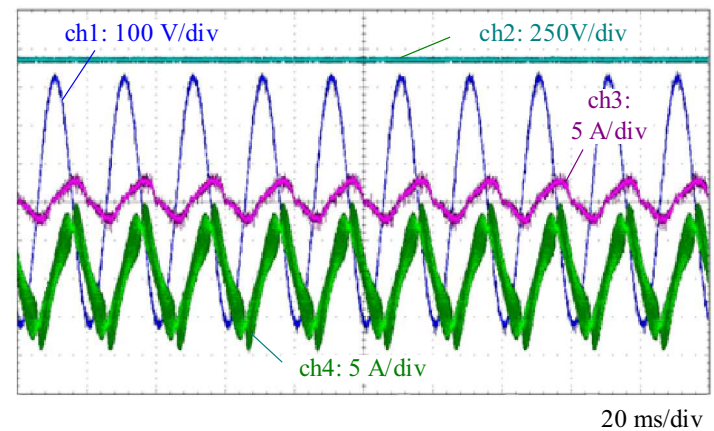

Fig. 13. Current source steady-stay for low vaulue of current (current components: $\left.i_{d w}=-1 \mathrm{~A}, i_{q w}=0 \mathrm{~A}\right)$, ch1: ac source voltage $V_{a c}$ $[100 \mathrm{~V} / \mathrm{div}]$, ch2: dc voltage $v_{d c}[250 \mathrm{~V} / \mathrm{div}]$, ch3: output current $i_{a c}$ [2A/div], ch4: current on converter side $i_{\text {conv }}[5 \mathrm{~A} / \mathrm{div}]$

Figure 8 presents converter behaviour during connection to ac source (ch1-ac source voltage) without switching (converter firing signals are blocked). The converter current ( $\operatorname{ch} 4 i_{\text {conv }}$ ) is zero, but the output current (ch3 $i_{\mathrm{ac}}$ ) reach the value around $5 \mathrm{~A}$. If the output current is required zero the converter must generates approximately the same value of converter current with opposite polarity as it is shown in Fig. 9. For required reactive current $i_{\mathrm{dw}}=9 \mathrm{~A}$, the start-up sequence of converter and steady state is shown in Fig. 10. The converter transient is very fast, but control algorithm spends more time for current distortion elimination. These current deformations 
are removed by resonant controllers (harmonic compensation part). The problematic state is captured in Fig. 11 where the start-up sequence of converter for current requirement $i_{\mathrm{dw}}=-9 \mathrm{~A}$ is presented. In this case, the current distortion elimination takes several periods and stabilization (steady-state) is shown in Fig. 12. After converter shutdown, the current oscillation is very well visible (current $i_{\mathrm{ac}}, \operatorname{ch} 3$ in Fig. 12). The oscillation frequency is equal to natural frequency of LCL filter. The most problematic converter states are small currents requirements (from $0 \mathrm{~A}$ to $2 \mathrm{~A}$ ). The main problem came from current measurement accuracy, converter non-linearity and current control response. Converter behaviour under requirements for $1 \mathrm{~A}$ is depicted in Fig. 13.

\section{CONCLUSION}

The paper presents new control structure of current source with LCL output filter. The output LCL filter provides low output current $\left(i_{\mathrm{ac}}\right)$ ripple compared with converter current $\left(i_{\text {conv }}\right)$. However, systems incorporating LCL filters require more complex control strategies. The paper describes control algorithm based on structure with a feedback direct current control based on resonant controllers and feedforward single-phase vector control as a LCL filter compensator. Designed control provides fast dynamic control of LCL filter output current and resonant controllers compensates 3 th, 5th, and 7th harmonics of the output current caused by nonlinear behavior of IGBT converter. The proposed control technique is verified by experiments made on developed small-scale converter prototype with $2 \mathrm{kVA}$ output power.

\section{Acknowledgement}

This research has been supported by the European Regional Development Fund and Ministry of Education, Youth and Sports of the Czech Republic under project No. CZ.1.05/2.1.00/03.0094: Regional Innovation Center for Electrical Engineering (RICE) and project No. SGS2015-038.

\section{REFERENCES}

[1] LEE, C. K.-LEUNG, J. S. K.-HUI, S. Y. R.-CHUNG, H. S. H. : Circuit-level comparison of STATCOM technologies, Power Electronics, IEEE Transactions on 18 No. 04 (2003), 1084-1092.

[2] HAMED, H. D.-MASOUD, M. S.-HOSSEIN, A. A.-MOHAMMAD, R. J. : A new approach to optimize the apfs placement based on instantaneous reactive power theory by genetic algorithm, Journal of Electrical Engineering - Elektrotechnický časopis 65 No. 01 (2014), 12-20.

[3] BEIROVI, E.-OSMI, J.-KUŠLJUGI, M.-PERI, N. : Analysis and synthesis of model reference controller for variable speed wind generators inertial support, Journal of Electrical Engineering - Elektrotechnický časopis 66 No. 01 (2015), 3-10.

[4] RAKOVÁ, L.-DVORSKÝ, E. : Voltage and frequency control for islanded microgrids containing photovoltaic power plants, Journal of Electrical Engineering - Elektrotechnický časopis 65 No. 07 (2014), 9-14.
[5] ZEMAN, M.-PEROUTKA, Z.-KOMRSKA, T. : Application of hybrid delta modulation for control of single-phase voltage source active rectifier, Applied Electronics (AE), 2010 International Conference on (2010), 1-4, IEEE, Pilsen 8-9 Sept. 2010.

[6] BAHRANI, B.-KARIMI, A.-REY, B.-RUFER, A. : Decoupled dq-Current Control of Grid-Tied Voltage Source Converters Using Nonparametric Models, Industrial Electronics, IEEE Transactions on 60 No. 4 (2013), 1356-1366.

[7] BLAHNIK, V.-TALLA, J.: Control of single-phase H-bridge power converter based on vector control, Clean Electrical Power (ICCEP), 2013 International Conference on (2013), 548-551, IEEE, Alghero 11-13 June 2013.

[8] PASTOR, M.-DUDRIK, J. : Predictive Control of Grid-Connected Multilevel Inverter with Output LCL Filter, Elektronika ir Elektrotechnika 21 No. 3 (2015), 10-15.

[9] KAMEL, O.-MOHAND, O.-TOUFIK, R.-TAIB, N. : Nonlinear predictive control of wind energy conversion system using dfig with aerodynamic torque observer, Journal of Electrical Engineering - Elektrotechnický asopis 65 No. 06 (2014), 333-341.

[10] YAPES, A. G. : Digital Resonant Current Controllers for Voltage Source Converters, University of Vigo, University of Vigo, Spain, 2011, pp. 1-183.

[11] BLAHNIK, V.-PEROUTKA, Z.-ZAK, J.-TALLA, J. : Elimination of dead-time effect causing current distortion of single-phase power converters, Power Electronics and Motion Control Conference (EPE/PEMC), 2012 15th International (2012), DS1e.3-1-DS1e.3-6, IEEE,Novi Sad 4-6 Sept. 2012.

[12] SONG, H. S.-KEIL, R.-MUTSCHLER, P.-Van der WEEM, J. - Nam, K. : Advanced control scheme for a single-phase PWM rectifier in traction applications, Industry Applications Conference, 2003. 38th IAS Annual Meeting 3 (2003), 1558-1565, IEEE, 12-16 Oct. 2003.

13] BLAHNIK, V.-PEROUTKA, Z.-TALLA, J. : Advanced control strategy for single-phase voltage-source active rectifier with low harmonic emission, Journal of Electrical Engineering - Elektrotechnický asopis 65 No. 02 (2014), 121-124.

Received 14 March 2015

Vojtěch Blahník, (Ing, $\mathrm{PhD}$ ) received the master and $\mathrm{PhD}$ degrees in Electrical Engineering from the University of West Bohemia, Pilsen, Czech Republic in 2006 and 2011, respectively. His research concerns power electronics, modern control methods of medium and higher-power converters.

Jakub Talla (Ing, PhD) received MS and PhD degrees in Electrical Engineering from the University of West Bohemia (UWB), Pilsen, Czech Republic, in 2006 and 2013, respectively. Since October 2010, he is a R\&D engineer at the Regional Innovation Centre for Electrical Engineering (RICE) at UWB. His main research interests include control of AC drives and grid-connected converters, predictive control, power management methods and soft computing techniques.

Zdeněk Peroutka, (Prof, Ing, PhD) received MS and $\mathrm{PhD}$ degrees in Electrical Engineering from the University of West Bohemia (UWB), Pilsen, Czech Republic in 2000 and 2004, respectively. He is Full Professor of Power Electronics and Control Systems and Vice-Dean for Science and Strategy at the Faculty of Electrical Engineering at UWB. Since October 2010, he is a Scientific Director and Principal Investigator of the Regional Innovation Centre for Electrical Engineering (RICE) at UWB. His main research topic is control of drives of modern transport systems and vehicles, and power electronics converters for medium-voltage applications. He published more than 100 papers in international journals and conferences. He is inventor of two patents and two utility models. 